\title{
Fantasmas e inflamaciones: reflexiones sobre las interpelaciones terapéuticas a la religión en India
}

Phantoms and inflammations: reflections on the intersections between therapeutics and religion in India

${ }^{1}$ Doctora en Antropología Social y Etnología. Profesora asociada, Université Paris Descartes, Francia. $₫$
RESUMEN Este artículo trata sobre la presencia y el rol clave de seres no humanos dotados de intención en el diagnóstico y la cura. Desde la corriente de estudios dedicados al pluralismo y los itinerarios de cura, se analiza la persistencia de la categoría del fantasma -entidad no humana dotada de intencionalidad- en los recorridos de curación, a la par de la biomedicina y sus categorías diagnósticas. Los datos que constituyen la base de este artículo fueron recogidos en el curso de numerosas estadías de campo etnográficas llevadas a cabo entre 2005 y 2015 en una red de pueblos situados en la región del Garhwal, en el distrito de Uttarkashi, que ocupa el área noroccidental de Uttarkhand, India. A partir de estos datos se intenta reflexionar sobre las razones por las cuales los pacientes, en determinados contextos, en el proceso de diagnóstico y curación, se dirigen a diferentes especialistas, incluso de forma simultánea.

PALABRAS CLAVES Religión; Terapéutica; India.

ABSTRACT This article looks at the presence and key role of nonhuman beings endowed with intention in the diagnosis and cure of illness. Based on the framework of studies of pluralism and itineraries of healing, the article reflects on the persistence of the category of the phantom - a nonhuman entity endowed with intentionality - in such paths of curation, alongside biomedicine and its diagnostic categories. The data upon which this article is based were collected over the course of numerous ethnographic field visits carried out between 2005 and 2015 in a network of villages located in the Garhwal region of the Uttarkashi district, in the area northwest of Uttarkhand, India. Using these data, the article attempts to reflect on the reasons why patients, in certain contexts throughout the diagnosis and healing process, seek out different specialists, often at the same time.

KEY WORDS Religion; Therapeutics; India. 


\section{INTRODUCCIÓN}

Gracias a su comprobada eficacia y a su asociación con el poder colonial y con la imagen de "modernidad", la biomedicina conquistó gradualmente en todo el mundo, en el curso de los últimos siglos, una preeminencia tal que puede ser hoy considerada como una de las exportaciones ideológico-prácticas más logradas de occidente ${ }^{(1)}$. Junto con sus prácticas e instituciones, ha llevado también a cada ángulo de la tierra su propia visión anatomofisiológica y mecanicista del cuerpo, que se pretende empírica, racional y definitivamente laica. El cuerpo sobre el que interviene hoy la biomedicina es un objeto profano. En efecto, el nacimiento de la medicina moderna y de su concepción del hombre está íntimamente ligada a su acto de emancipación del ámbito religioso. Si desde la antigüedad y durante siglos las prácticas terapéuticas y la religión estaban conectadas bajo múltiples formas ${ }^{(2)}$, a partir de la época moderna, la medicina ha cumplido una clara toma de distancia epistemológica respecto de la religión, haciendo de esta última un conjunto de valores subjetivos y morales y presentándose, por oposición a la religión, como un saber objetivo, científico, racional y universal ${ }^{(3)}$.

Con la eliminación de toda referencia religiosa, la biomedicina expulsó de su universo conceptual -en tanto causas potenciales de los males del cuerpo- también a espíritus, fantasmas, divinidades y, en general, a todos los agentes no humanos dotados de intencionalidad. En otros términos, la biomedicina fundó la propia práctica y doctrina de una etiología rigurosamente "no personal" en el sentido propuesto por Forster y Anderson $^{(4)}$. Según el modelo elaborado por estos autores, las prácticas e instituciones terapéuticas difundidas en el mundo se basarían, principalmente, en dos tipos de etiología: una, denominada por los autores "personalistic", haría derivar la enfermedad de la acción de los seres intencionales, es decir, que tienen creencias y deseos (divinidades, espíritus, espíritus de los muertos, etc.); y, la otra, "naturalistic", atribuiría el mal a una causa mecánica o natural como, por ejemplo, un desequilibrio que se produce entre elementos inanimados del cuerpo humano. La biomedicina se erigió, luego del proceso de distanciamiento de la esfera religiosa, como el saber médico naturalista y "no personal" por excelencia. Si bien es cierto que, aun desde el punto de vista biomédico, existen agentes humanos y no humanos -como virus y bacterias- que afligen el cuerpo y causan las enfermedades, son considerados rigurosamente desprovistos de intencionalidad y voluntad propia.

Así y todo, a pesar de este excepcional e innegable éxito a nivel global, la biomedicina no ha logrado conquistar el monopolio del campo de la salud y no ha podido secularizar el dominio de la cura. Prácticamente, todos los estudios dedicados al pluralismo médico han destacado cómo el recurso a la religión representa aún un recurso importante, tanto en occidente como en otros lugares del mundo, y cómo los seres no humanos dotados de intencionalidad intervienen activamente en el campo de la salud, en tanto agentes responsables de enfermedades y sanaciones ${ }^{(1,5,6,7)}$.

El estado de Uttarakhand, situado en el norte de la India, no es la excepción a esta tendencia. Si bien el paisaje terapéutico local es extremadamente variado (sistemas médicos considerados panindios como el ayurveda, la homeopatía o el yoga coexisten con prácticas locales de fitoterapia, masajes y manipulación, técnicas de cauterización, además de astrología y de prácticas diagnóstico-terapéuticas cumplidas por sacerdotes y por los médiums de las divinidades, etc.), la biomedicina ocupa una posición hegemónica desde el punto de vista ideológico y práctico. Sin embargo, aunque esta última sea la principal práctica médica financiada por el Estado y constituya a menudo una etapa importante en los recorridos de curación, son numerosos los casos en los que seres no humanos dotados de intención juegan un rol clave en el diagnóstico y la cura. Este texto se propone reflexionar sobre los motivos de la presencia persistente de tal categoría de agentes en el campo de la salud, a la par de 
la biomedicina, y de sus categorías diagnósticas. Esta pregunta es explorada a partir de la figura del fantasma -entidad no humana dotada de intencionalidad por excelencia- y de la acción atribuida a los fantasmas en los recorridos de curación. Uttarkhand, una de las regiones más pobres de la India reviste, desde noviembre de 2000, la figura administrativa de estado autónomo de la República Federal India. La mayoría de la población vive en las zonas montañosas del estado que, así como la región en que esta investigación fue llevada a cabo, forman parte del sistema montañoso del Himalaya. En tales áreas, la economía local se sostiene principalmente en el trabajo de la población agrícola, las remesas de dinero de los parientes emigrados a la ciudad para trabajar en diversos sectores $y$, en menor medida, en la cría de ganado.

\section{ACERCA DE LA INVESTIGACIÓN}

Los datos que constituyen la base de este artículo fueron recogidos en el curso de numerosas estadías etnográficas de campo llevadas a cabo entre 2005 y 2015 en una red de pueblos situados en la región del Garhwal y, más precisamente, en el distrito de Uttarkashi, que ocupa el área noroccidental de Uttarkhand. La investigación se desarrolló primero en el marco de una tesis de doctorado ${ }^{(8)}$ consagrada a las prácticas de posesión oracular y, sucesivamente, en el ámbito de un programa de investigación colectiva (Project Présence d'esprits, 2013-2018) financiado por la Agence Nationale de la Recherche (ANR). Estas investigaciones, conducidas tanto individualmente como en compañía de asistentes locales, requirieron largas estadías en los poblados, que permitieron construir una relación de intimidad con una o dos familias por pueblo, para después, a través de tales familias, ser aceptada por la comunidad y poder entonces observar "desde cerca" la vida cotidiana de estas colectividades. Los habitantes de los poblados fueron informados del propósito de esta investigación y no solo aprobaron la obtención y el tratamiento de los datos, sino que también ofrecieron, en la mayor parte de los casos, una ayuda generosa, colaborando activamente en la integración de la autora de este texto en sus redes de amigos y parientes.

\section{Recorridos de cura y agentes invisibles: abordaje teórico}

Enfocando el rol de los fantasma en los recorridos de diagnóstico y tratamiento que toman forma en un paisaje terapéutico plural, este texto se inscribe en la corriente de estudios dedicados al pluralismo y a los itinerarios de cura, o sea los estudios que analizan los modos y las razones por las cuales los pacientes, en un determinado contexto, se dirigen a uno $u$ otro especialista, e incluso a diferentes especialistas de forma simultánea ${ }^{(7)}$. Muchos de estos estudios adoptan un abordaje centrado en la "representación" y recurren a nociones afines al "modelo explicativo de la enfermedad" conceptualizado por Kleinman ${ }^{(9)}$ y luego aplicado al estudio de los recorridos terapéuticos por numerosos autores ${ }^{(10)}$. Los modelos explicativos de la enfermedad son discursos sostenidos por los enfermos para dar un sentido coherente a sus síntomas, a las causas, a las circunstancias que originaron la enfermedad y a las posibles terapias, es decir, a toda la experiencia de la enfermedad. Aunque aún está muy difundido, este abordaje ha sido criticado por numerosas razones, que podemos resumir brevemente en tres categorías: por su inclinación a sistematizar excesivamente el comportamiento de las personas ${ }^{(11)}$, porque tendería a considerar a los actores sociales como seres racionales y no como personas de carne y hueso, cuyo comportamiento está determinado también por elementos no cognitivos como la emoción y las sensaciones $^{(12,13)}$ que pueden estar, por lo tanto, en contradicción con sus representaciones ${ }^{(14,15)}$; $y$, finalmente, porque no toma en cuenta la lógica de la praxis en términos de Bourdieu. Este último mostró con claridad que las prácticas no son ni secundarias ni se oponen a las representaciones, sino que son mutuamente constitutivas: algunos autores han mostrado 
recientemente cuán cierta es esta asociación también en el campo de la salud ${ }^{(1)}$.

Partiendo de esta última perspectiva $-y$, por lo tanto, oponiéndose a las perspectivas sistematizantes, racionalizantes y basadas en la representación- las páginas que siguen proponen ampliarla aún más a partir de un abordaje que se inspira al mismo tiempo en la teoría de la práctica de Pierre Bourdieu ${ }^{(16)}$ y en el trabajo de Mijaíl Bajtín sobre la relación dialógica. Según la perspectiva sugerida por la fusión del dialogismo y de la teoría de la práctica, los modos de gestionar socialmente los eventos (la enfermedad, en este caso) no dependen solo de la relación entre prácticas y estructuras, sino también de las interpretaciones que los actores formulan en cada situación en relación con sus interacciones intersubjetivas, sus experiencias personales y una racionalidad que toma forma en el contexto particular. Es precisamente el contexto situacional el que demanda la adopción de determinados valores y puntos de vista y que, según el momento, lleva a los actores a elegir su prioridad ${ }^{(16,17)}$. Para comprender las acciones es necesario analizarlas no solamente en relación con el orden de la estructura y de las representaciones culturales, sino también en función de un contexto situacional, en el que otros eventos se producen y en el cual otras personas formulan interpretaciones y valoraciones, realizan acciones y persiguen objetivos. Este abordaje asigna, entonces, la misma importancia - para los fines de la comprensión de los hechos sociales- a las prácticas de los actores, a las estructuras sociales y culturales dentro de las cuales esas prácticas se inscriben (relaciones preexistentes, disposiciones incorporadas, representaciones compartidas); y a los factores situacionales (contingencias e intersubjetividades).

Incluso, en una circunstancia concreta, la utilización del discurso que atribuye un problema de salud a una acción de fantasmas debe ser examinado a partir de la consideración del conjunto de estos elementos. Lejos de ser una "creencia", una representación mental abstracta, este es un discurso que emerge en situaciones concretas y en el curso de un proceso gradual. Las páginas que siguen apuntan a comprender el corazón de este proceso. Para esto se enfocan en el microanálisis de un caso de sufrimiento físico, que terminó siendo atribuido a la acción de un fantasma y tratado y resuelto como tal. Como ejemplo de eventos similares que se producen en la región, este caso de enfermedad puede ser considerado como una ocasión fecunda para mostrar el modo en que los fantasmas concretamente "toman vida" como hipótesis causal de eventos en el ámbito de la salud.

\section{Del proceso inflamatorio al fantasma}

\section{El diagnóstico biomédico}

Durante el período de la siembra del trigo en el año 2006, Rajni Rana, una mujer perteneciente a una categoría jerárquicamente elevada en el sistema hindú de castas (rājpūt) y residente en el pueblo multicastas de Seni, comenzó a sufrir un dolor en la pierna derecha. Solo en el momento en que el dolor se volvió insoportable, y cuando ya no podía evitar renguear $y$, por lo tanto, esconder la existencia del problema, lo confesó a las mujeres de la familia patrilocal. Tuvieron que pasar aún dos semanas -durante las cuales los síntomas empeoraron aún más- antes que Rajni obtuviera de su marido el permiso para ir a la clínica médica más cercana en los alrededores de su pueblo. El médico le diagnosticó una severa inflamación, fruto de un esguince muscular, y le diagnosticó una pomada, un fármaco antidolor y dos semanas de reposo. Sin embargo, al volver a su casa, el marido le informó que solo se le concederían cuatro días de reposo. Esto significaba, le explicó, un costo ya muy alto para la familia: en ese momento la siembra estaba en curso y el trabajo de los campos no podía sufrir retraso alguno. En esos días la familia de Rajni se había visto obligada a contratar, por necesidad de mano de obra, a un operario de origen nepalés. Al término de esta breve licencia, la mujer retomó su trabajo y continuó aplicándose la pomada prescripta por el médico y, a la noche, compresas de agua y sal. 


\section{La divinidad de la casa y el fantasma}

Una noche como las otras, mientras cenábamos en la cocina, Rajni, su marido, los dos hijos varones y yo, sucedió un episodio destinado a dar una dirección nueva al proceso de interpretación del síntoma apenas descripto. El hijo mayor de Rajni, Anil, comenzó de repente a temblar, a respirar agitadamente, luego a jadear ruidosamente. Un instante más tarde, la cabeza del joven, como desarticulada del resto del cuerpo, giraba en varias direcciones. El joven se levantó de un salto repentino, tomó un tizón incandescente del fuego y lo acercó a la madre, con violencia, casi como si quisiera marcarle el rostro. Luego gritó, muchas veces, con ira: "Jā! Yahā! se jā!" (¡Vete! ¡Vete de aquí!). Un momento más tarde, Anil tomó a su madre por los cabellos y la arrastró fuera de la cocina, al patio contiguo. Todos corrieron afuera, siguiendo a Anil y Rajni. Entretanto, el marido de la mujer ordenó al hijo menor ir en busca de arroz. El hermano de Anil entró a la cocina y salió con un puñado de arroz que el padre puso en la cabeza de Anil, saludando y alabando al dios Nār Singh. Cuando el padre le colocó el arroz en la cabeza Anil, que durante todo ese tiempo seguía temblando y respiraba agitadamente, comenzó a calmarse. En pocos segundos, su respiración se normalizó; las manos, que aún aferraban los cabellos de su madre, aflojaron la presa y cayeron a lo largo del cuerpo. Anil, de pie, permanecía inmóvil. Luego el joven cerró los ojos por un instante, cuando los reabrió su mirada era de nuevo la de siempre, presente y vivaz. Cuando la escena terminó, la cuñada de Rajni, que había acudido con otros familiares al oír los gritos, acompañó a la conmocionada mujer a su habitación.

En el patio de la casa quedaron los varones, que se pusieron a debatir sobre lo que había sucedido. El dios Nār Singh se había manifestado ese día por primera vez en el cuerpo de Anil, y había tratado de echar a una entidad nefasta del cuerpo de Rajni. Nār Singh es una divinidad local y divinidad del linaje ( $k u l$ devtā) de la familia del marido de Rajni. Anil, que decía no recordar nada, fue informado del episodio.

\section{El fantasma declarado responsable del síntoma}

Algunas semanas más tarde, Rajni fue llevada al templo de Kandaar, la divinidad tutelar del pueblo, para someter el hecho al veredicto adivinatorio de su palanquín. Este proceso adivinatorio forma parte de una práctica ampliamente difundida en el valle en el que se llevó a cabo la investigación y en sus áreas limítrofes, situadas en Uttarkhand y el estado de Himachal Pradesh. En tanto miembros de un poblado y ocupantes de un cierto territorio, los individuos se dirigen continuamente y deben obediencia a la divinidad (un dios, o más raramente una diosa) que gobierna sobre este espacio como si fuera un rey: la categoría a la que estas divinidades pertenecen se denomina, en virtud de su lazo con el territorio (grām), grām devtā, si es un dios masculino, y grām devī, si es una diosa femenina. Estas divinidades poseen casi siempre un palanquín de madera que, cuando debe ser interpelada por los devotos, se acomoda sobre los hombros de sus portadores oficiales, dos hombres considerados como "elegidos" para tal función por la misma divinidad. En el momento de la consulta, los portadores del palanquín comienzan a moverse, a inclinarse y a oscilar en varias direcciones: se sostiene que, en tales momentos, es el mismo palanquín el que se mueve autónomamente y que los portadores solo siguen los movimientos. Considerados como la modalidad de expresión de las divinidades, tales movimientos son interpretados y "traducidos" por devotos y consultantes, por personas pertenecientes al grupo de aquellos que, en cada poblado, se consideran expertos en la comprensión de esta forma de lenguaje divino.

El dios Kandaar confirmó, a través de su palanquín, la hipótesis que ya circulaba en el poblado, enriqueciéndola con más detalles: el espíritu errante de una víctima de uno de los peores terremotos de la historia de la región (que tuvo lugar en 1991) se había pegado (lag gayaa) al cuerpo de Rajni en el curso de uno de los numerosos desplazamientos que ella había llevado a cabo en los últimos meses entre su poblado 
de residencia actual y su pueblo de origen. Después de haberse "pegado" de alguna manera a su cuerpo, el espíritu no se limitaba a causar síntomas físicos como el problema de la pierna, sino que la empujaba a tener comportamientos inapropiados. El primero, entre ellos, el hecho de ausentarse frecuentemente del poblado conyugal, en períodos cruciales para la actividad agrícola y, por lo tanto, para la economía doméstica. De acuerdo con un modelo muy común en este tipo de situaciones, el comportamiento de la mujer es considerado al mismo tiempo como la causa y la consecuencia del ataque por parte del fantasma, porque el acto imprudente de atravesar con frecuencia el espacio externo del poblado conyugal fue visto como la causa principal del ataque pero, también, de una cierta manera, como una acción causada por la presencia del fantasma en el cuerpo de la mujer. Rajni había realizado, efectivamente, numerosas visitas a su pueblo natal (mait), ausentándose a menudo de la casa del marido. Alrededor de seis meses antes había participado en el matrimonio de un sobrino y se había quedado en la casa de sus padres durante varios días. Una segunda vez, cuatro meses antes, había sido Ilamada a su pueblo por una grave enfermedad del padre. La última de estas visitas tenía origen en su voluntad de participar de la ceremonia de tonsura (mumdan) de otro sobrino. Rajni contaba que este último hecho había tenido lugar en pleno período de labores agrícolas (el período del rupāī o del trasplante del arroz) y que, por lo tanto, el marido había tratado insistentemente de disuadirla de ausentarse nuevamente de su casa.

La divinidad tutelar del pueblo ordenó someter a la mujer a un tratamiento ritual Ilamado rakhvāli ya descrito en otro trabajo ${ }^{(18)}$, destinado a la extracción de fantasmas del cuerpo de las personas consideradas víctimas de un ataque. La organización de este ritual y su ejecución expulsa definitivamente el evento que afecta el cuerpo de Rajni fuera de la escena doméstica, para transformarlo en un problema que involucra a todo el pueblo. De hecho, el rito no tiene el fin único de curar a la persona sufriente, sino también el de crear una barrera de protección del territorio del poblado entero para evitar el regreso del fantasma y el ataque de otros eventuales espíritus errantes o de otros seres peligrosos. El rito tiene además una naturaleza colectiva, porque debe ser realizado por un conjunto de expertos rituales: la divinidad tutelar del poblado y su palanquín, sus portadores y sus oficiantes, los médiums de algunas divinidades -consideradas expertas en este tipo de operaciones de extracción- y a menudo los médiums de las divinidades del linaje de la persona que oficia el rito. La palabra médium es utilizada en este artículo para indicar figuras de poseídos institucionales -llamadas localmente paśvā- especialistas de una forma de posesiones por parte de divinidades $u$ otras entidades no humanas que, a diferencia de las posesiones no deseadas (por ejemplo, la posesión por parte del fantasma) es auspiciada, organizada e institucionalizada porque es considerada una fuente de adivinación y de otros favores por parte de las divinidades a través de sus poseídos. Luego de la ejecución del ritual, Rajni se declaró curada y retomó en seguida sus actividades.

\section{La instauración de la relación entre fantasma y síntoma: prácticas, estructuras y aspectos situacionales}

El dolor que afectaba al cuerpo de Rajni se vio sometido, durante varias semanas, a un proceso gradual de interpretación. ¿Por qué razones la figura y la acción del fantasma terminan por prevalecer sobre otras posibles interpretaciones? ¿Cuáles son las representaciones y los órdenes relacionales sobre los que esta interpretación reposa, las circunstancias situacionales que le permiten afirmarse, las emociones e inquietudes que la nutren, las elecciones o las estrategias individuales y colectivas a las que es funcional? Para comprender estos elementos es necesario un análisis que observe la creencia en el fantasma en su devenir concreto, en un equilibrio complejo entre prácticas, estructuras y elementos situacionales. 


\section{La estrategia de Rajni y el valor del honor}

Rajni participa activamente en la gestión de su propio síntoma, poniendo en práctica, de forma más o menos consciente, aunque no sean auténticas estrategias, al menos elecciones. Esta capacidad de elección puede, sin embargo, ejercitarse en los límites definidos por los valores y las representaciones compartidas, los órdenes relacionales y las consecuencias temporales. Así, cuando surge el dolor, la acción de Rajni, caracterizada, en esencia, por la no acción y el soportar silenciosamente el dolor, es dictada por un saber incorporado sobre el comportamiento apropiado de los sujetos femeninos en la sociedad garhwali. El sentido del honor (izzat) y el intento de evitar el comportamiento deshonorable (beśaram) constituyen motivos recurrentes a nivel discursivo y cumplen un rol clave en la orientación de las prácticas de los actores sociales. El honor es un concepto fluido y situacional, conectado con la identidad de género y relativo a la edad y al estatus de la persona. En las distintas fases de su vida los individuos de ambos sexos se guían por un conocimiento incorporado sobre qué comportamientos son adecuados a cada edad y estadio: tal sentido práctico les permite orientar las propias prácticas hacia la conservación del patrimonio de honor. Para una mujer casada, que vive en la casa del marido, esta disposición incorporada incluye la capacidad de soportar un duro trabajo cotidiano y de cumplir las múltiples y pesadas tareas agrícolas y pastoriles que forman parte de sus tareas. El honor de la mujer, antes y después del matrimonio, influencia directamente el honor de la colectividad a la que pertenece: la casa natal y el poblado antes del matrimonio, la casa y el poblado del marido, pero también la colectividad de origen después del matrimonio. El capital de honor es entonces precioso para las esposas no solo para acrecentar su poder dentro de la familia del marido, sino también a los fines de conquistar la estima de toda la comunidad del poblado conyugal y de preservar el honor de la familia y del poblado natal ${ }^{(19)}$. Por este motivo, Rajni decide revelar su sufrimiento solo cuando este se vuelve tan fuerte que le impide trabajar y, por lo tanto, es imposible de esconder. Luego de la revelación, ella logra el permiso del marido para asistir a una consulta médica y recibir un diagnóstico. El hecho de consultar a un médico, antes que ir de inmediato al templo para un diagnóstico oracular, es fruto a su vez de una elección dictada con toda probabilidad por la intención de dar a su problema un cierto tipo de interpretación. Las numerosas posibilidades diagnósticas locales se organizan en efecto en un continuum, según la diferente incidencia que tiene en la explicación el contexto de la vida social. En un extremo del continuum se ubican las explicaciones que presuponen de manera más o menos directa que la aflicción deriva de una fractura entre humanos o entre humanos y no humanos, susceptible de haber causado consecuencias como una sanción divina (dos), magia negra (jādū) o un ataque de brujería (ghāt) de una persona contra otra. Estas explicaciones imponen a los individuos, a los fines de la cura y de la resolución del problema, un examen de sus propias responsabilidades en su red de relaciones: es indispensable comprender de dónde proviene el problema antes de decidir la acción ritual necesaria para resolverlo (por ejemplo, un rito de ofrecimiento para reparar la sanción divina o un contraataque de brujería). En el otro extremo del continuum encontramos las características diagnósticas basadas en mecanismos de causa efecto (presencia de bacterias o desequilibrios de humores, por ejemplo) que son consideradas independientes del contexto de la vida social, que no convocan responsabilidades sociales, rituales o divinas y cuya resolución es competencia del médico: la categoría localmente utilizada para este tipo es la de rog, traducible como enfermedad basada en mecanismos de tipo fisiológico. Dado que los médicos solo diagnostican y proporcionan remedios de este tipo, se puede afirmar que en Garhwal los diagnósticos de los médicos proporcionan a los individuos instrumentos para hacer de sus propios problemas físicos rog, o sea, enfermedades que no tienen una causa sobrenatural y ninguna relación con 
responsabilidades rituales o con desórdenes sociales. En modo similar a lo observado por Fainzang ${ }^{(20)}$, cerca de Bisa, en Burkina, el acto de Rajni puede ser entonces leído como un intento estratégico -tal vez solo parcialmente consciente- de inclinarse por un diagnóstico médico y de escapar así a la actividad oracular y al control social que esta impone.

Aun así, el esfuerzo de Rajni de hacer de su propia enfermedad un rog está destinado al fracaso. En un momento de gran intensidad del trabajo agrícola, la mujer no obtiene la licencia de reposo. Esto contribuye a la persistencia del síntoma y abre un espacio en el que otras oportunidades de gestión del problema se vuelven posibles. Es en este espacio en el que se inserta el episodio de posesión del hijo Anil, vuelto posible (pero, recordémoslo una vez más, no obligatorio) por las representaciones compartidas sobre la posesión y por otros elementos estructurales, que serán analizados en el próximo apartado. Luego de este episodio, una nueva hipótesis diagnóstica pudo desarrollarse: Rajni adapta entonces su comportamiento a la nueva situación. Su "saber práctico"(16) le impone ahora someterse con obediencia al veredicto de las divinidades. En ese momento, su respeto por la institución adivinatoria local es lo que está en juego, y el rechazo a adherir a su veredicto implicaría consecuencias muy negativas para su honor y su posición en el hogar conyugal. Esto muestra cómo cambian, en función del contexto, las prioridades del sujeto, Rajni, en este caso.

\section{La acción de Anil y la posesión}

El episodio que describimos fue el primero en el que Nār Singh, divinidad de linaje de la familia, se manifestaba públicamente en el cuerpo de Anil. Sin embargo, los gestos y las palabras de este fueron recibidos por los presentes como signos evidentes e incuestionables de la presencia del dios del linaje, y sus actitudes fueron interpretadas como el acto a través del cual un dios, encarnado en un soporte humano, trata de expulsar a un espíritu. La eficacia de la performance del joven es tal que, en pocos minutos, decreta que la madre es víctima del ataque de un fantasma. Durante las semanas siguientes esta hipótesis no solo no se discutirá, sino que será completada y enriquecida. ¿Por qué el gesto de Anil es tan eficaz?, ¿era este el único resultado posible de su acción?

El idioma corporal de la posesión es un orden simbólico cultural y socialmente relevante, que presupone, por parte del médium y de los "espectadores", un conocimiento incorporado de las reglas de la cultura y de las circunstancias que vuelven creíble un episodio de posesión o, en otras palabras, un conocimiento de los criterios de eficacia de una performance entendida en el sentido sugerido por Víctor Turner ${ }^{(21)}$, como puesta en escena del propio cuerpo, en gran medida inconsciente, que tiene efectos sociales concretos. El hecho de agredir a otro individuo acercándole un tizón ardiente (o a veces una rama de ortiga, o un pedazo de hierro incandescente) entre el rostro y los hombros, en el contexto local, puede recibir dos sentidos principales: por un lado, puede ser considerado un comportamiento fruto de la ficción o, por el otro, un signo de la presencia de un espíritu en la persona amenazada o de una divinidad en la persona que amenaza. Ahora bien, las representaciones compartidas respecto de las modalidades más frecuentemente usadas por las divinidades en la elección de aquellos a quienes poseen crean expectativas en las comunidades y constituyen un ingrediente fundamental en la predeterminación de las probabilidades de éxito o de fracaso de una performance de posesión. Si las divinidades del linaje de la familia Rana privilegian a los poseídos varones, una serie de circunstancias volvían la posesión del joven aún más plausible. El hermano del abuelo de Anil, actual médium de Nār Singh, era ya más bien anciano y, por motivos de trabajo, estaba a menudo ausente del poblado; Anil era (y es) un joven respetado en Seni por su devoción y atención a las necesidades de familiares y parientes; el hermano y los primos, muy a menudo dedicados a las correrías en la capital de distrito Uttarkashi, no gozan de la misma buena fama que él en el ámbito de la casa y del poblado. Por todos estos motivos, desde 
tiempo atrás, en la familia circulaban rumores que aludían a la posibilidad de que el dios Nār Singh se encarnara un día justamente en Anil. Preparada por estas expectativas, acontecida en presencia de familiares sentados en torno al hogar doméstico y en el momento en el cual una circunstancia problemática requería resolución urgente (la enfermedad de la madre en un período de intenso trabajo agrícola), la posesión de Anil fue recibida como una genuina manifestación de la presencia de la divinidad del linaje.

Pero el éxito del gesto de Anil y el del diagnóstico que ese gesto implícitamente postulaba no pueden ser comprendidos plenamente sin tomar en consideración algunos elementos que componen el marco más vasto en el que se radican, en primer lugar, las representaciones compartidas sobre el cuerpo y la naturaleza femenina.

\section{Fisiología femenina}

El predominio de las mujeres como víctimas de la posesión por parte de espíritus de los muertos es observada por numerosos autores en Asia del Sur ${ }^{(22,23,24)}$ como en otros contextos $^{(25)}$. En Garhwal la mayor propensión de la mujer a ser atacada por espíritus y fantasmas está ligada a una visión específica de la fisiología y de la naturaleza femenina. Las mujeres son vistas, en este sentido, como dotadas de algunas características que las identifican con los fantasmas. Son estas mismas características las que las vuelven particularmente vulnerables al ataque de los fantasmas. Antes que nada, su cuerpo es considerado parcialmente kaccā, literalmente crudo, no cocido. Por esta razón es particularmente permeable y, por lo tanto, más expuesto en comparación con el de los hombres- al ataque de distintos tipos de influencias. A esta característica física se agrega un rasgo de carácter también considerado típicamente femenino, que agrava el riesgo de ataque por parte de fantasmas: el ser miedosa (darāū). Si bien se dice que el ataque por parte de los espíritus se vuelve más probable por una configuración del horóscopo desfavorable: el estado de miedo es por antonomasia la condición que vuelve concretas las circunstancias del ataque. Cuando una mujer atraviesa un lugar externo a su propio poblado (considerado, junto con los campos que lo rodean, el único lugar seguro para una mujer) es bastante probable que esté atemorizada y tensionada. Por lo tanto, es frecuente que un espíritu "aproveche" este momento de vulnerabilidad para hostigarla. Una tercera característica natural vuelve a las mujeres más susceptibles a los ataques: la inclinación a la inestabilidad de pensamientos y emociones (camcal). En los momentos en que este rasgo de carácter deviene estado de ánimo -la falta de focalización o "la cabeza llena de pajaritos" - expone al sujeto al ataque de fantasmas.

Finalmente, después de la pubertad, la mayor exposición de las mujeres a la impureza ocasionada por sus ciclos corporales las vuelve físicamente aún más vulnerables a los fantasmas.

Estas cualidades naturales del cuerpo y del carácter femenino constituyen el soporte en que se arraigan las normas sociales que regulan su comportamiento. Desde la adolescencia, el autocontrol se convierte en una cualidad esencial para las mujeres, que atañe tanto al control de los movimientos internos, o sea de las propias emociones, como de los movimientos externos, es decir, de los comportamientos, gestualidades y desplazamientos.

\section{Matrimonio, relaciones de parentesco y desplazamientos de la mujer}

A las representaciones compartidas sobre la fisiología y la naturaleza femeninas y a la necesidad de control que deriva de ellas se suma un importante elemento estructural útil para explicar la mayor propensión de las mujeres a ser consideradas víctimas de fantasmas: el contexto de las relaciones de poder desiguales que caracteriza a la familia garhwali y la condición de la mujer casada en el seno de tal tejido relacional.

La ideología dominante postula aquí, como en otros contextos hindúes ${ }^{(26)}$, una asimilación completa de las mujeres casadas al 
linaje del marido y una separación total del de sus padres, al punto que la esposa es considerada, después del matrimonio, la mitad del cuerpo del marido: se piensa que ella asume el estatus del marido y se vuelve una sola cosa con él y su familia. Tal ideología se refleja en los rituales procesionales que suceden al matrimonio en Garhwal: la joven esposa es acompañada desde la casa natal al poblado conyugal por una procesión que puede ser considerada como un potente medio simbólico para producir la separación del poblado natal y la agregación a la familia y al poblado del marido. Sin embargo, junto con la ideología dominante, la cultura local de la región de Garhwal prevé prácticas rituales y profanas (gestos de sostén recíproco, rituales, intercambios de regalos) que contribuyen a reforzar y mantener particularmente vivo (más que en otros contextos surasiáticos) el lazo de la mujer casada con la familia de origen. La más importante de estas prácticas es, sin duda, el desplazamiento continuo de las mujeres entre mait (poblado o casa natal) y sauryā (poblado o casa conyugal). Se observó que este es uno de los motivos culturales centrales tanto en Garhwal ${ }^{(27)}$ como en el limítrofe Kumaon ${ }^{(28)}$. Numerosos cantos rituales, canciones populares y proverbios se refieren al tema de las visitas de mujeres a su casa natal, a la alegría del encuentro entre una mujer y sus seres queridos, a la infelicidad de las mujeres que no tienen la posibilidad de visitar a su familia de origen. Durante los períodos de menor intensidad del trabajo agrícola, las mujeres se desplazan con facilidad, a menudo, para visitar a las familias de origen. Otras ocasiones en las que la presencia de las "hijas del poblado" (las mujeres nacidas en el pueblo pero que residen en otro lugar) es requerida con insistencia son las festividades de las divinidades territoriales de los poblados de origen; pero también los matrimonios y otros rituales celebrados en la familia natal constituyen para las mujeres casadas ocasiones para visitar a su propia mait. Si estas prácticas de desplazamiento son muy frecuentes durante los primeros años de matrimonio, con el nacimiento de los hijos y las mayores responsabilidades que estos generan, las visitas de las mujeres a la casa de sus padres se vuelven más espaciadas; esto no significa, sin embargo, que el lazo con la mait se debilite. Del conjunto de estas evidencias etnográficas se deduce que la condición de la mujer casada es en Garhwal particularmente ambigua, y que su identidad reposa en un equilibrio precario entre una doble pertenencia que a menudo deviene ocasión de conflicto.

Inscriptos en este marco estructural, los posicionamientos de los actores y sus acciones, como el intento de Rajni de hacer de su problema un rog y la posesión del hijo Anil se vuelven más comprensibles. El comportamiento de la mujer había suscitado recientemente numerosas críticas y generado una tensión doméstica que no había encontrado resolución. El gesto de Anil durante la posesión constituye de por sí una hipótesis diagnóstica que, al crear una relación causaefecto entre la acción del fantasma y el síntoma de la madre, busca al mismo tiempo resolver esta tensión. En efecto, ese diagnóstico permite aludir de un modo indirecto y enmascarado a una tensión que todos los demás actores conocen, sin tener que expresarla directamente, lo que equivaldría a producir una fractura. Durante todo el proceso de interpretación, ninguna acusación explícita se dirigió a la mujer. Sin embargo, por medio de la atribución de responsabilidad a un agente externo (el fantasma) se aludió de modo indirecto al peligro al que la mujer se expuso y, por lo tanto, a su error y a su responsabilidad en el desarrollo de los hechos.

Muchos estudios vieron en la posesión femenina por parte de espíritus y fantasmas una forma de resistencia contra el poder ejercido sobre ellas ${ }^{(25,29,30)} \mathrm{o}$ un instrumento para articular conflictos psicológicos ${ }^{(23)}$. El caso de Rajni muestra, al contrario, cómo el idioma de la posesión por parte del fantasma es, más que una forma de resistencia, una manera de ejercitar un control sobre el sujeto femenino o, por lo menos, de hacer llegar una amonestación para Ilamarla al orden. Una interpretación similar de la posesión por parte de espíritus y fantasmas es sugerida por Richard Stirrat ${ }^{(31)}$ : en el santuario singalés de Kudagama el diagnóstico de posesión por parte de un espíritu demoníaco es la expresión 
del poder de control de los familiares de una mujer sobre su cuerpo y su comportamiento. Isabelle Nabokov ${ }^{(22)}$ llegó a conclusiones análogas: ella analiza la posesión demoníaca de las jóvenes esposas en Tamil Nadu, y ve en el exorcismo un instrumento simbólico para encuadrar la sexualidad femenina y empujar a las mujeres a conformarse con las expectativas culturales referidas al rol de la "buena mujer". En nuestro caso, el diagnóstico que termina por imponerse -y que, recordémoslo, atribuye el origen del problema a un ataque sobrevenido mientras Rajni atravesaba un espacio peligroso que ella no tendría que haber recorrido asiduamente- permite proteger la relación conyugal del conflicto, incitando a Rajni a corregir su propio comportamiento.

\section{Factores situacionales}

Finalmente, es necesario tomar en cuenta el contexto temporal en el que el episodio se inscribe. En otros casos analizados ${ }^{(9)}$, mujeres casadas logran con facilidad hacer reconocer un síntoma como un rog, un problema exclusivamente físico. Aun así, el dolor de Rajni se manifiesta en uno de los momentos más importantes del calendario agrícola: la siembra del trigo. La larga espera de Rajni antes de revelar su dolor así como el hecho de que la familia le dé solo algunos días de reposo, tiene que ser puesto en relación con esta temporalidad específica. La conclusión del episodio no habría sido probablemente la misma si el dolor se hubiera manifestado en uno de los períodos de actividad agrícola poco intensa. Con reposo, probablemente la pierna se habría desinflamado y esto no hubiera dado lugar a que otra hipótesis diagnóstica se afirmara. La falta de reposo determinó la persistencia del síntoma. Por otra parte, en el contexto local se espera un efecto casi inmediato de las medicinas alopáticas. Por eso, la persistencia de los síntomas luego de la ingesta de los fármacos es a menudo considerado una prueba del hecho de que el problema no deriva de una causa fisiológica y que debe ser, por lo tanto, interpretado y resuelto a través de otras categorías causales y otro tipo de remedios.

\section{CONCLUSIÓN}

Como muestran varios trabajos sobre el pluralismo médico, es difícil poder encontrar regularidades en los recorridos diagnósticos y terapéuticos, o en la sucesión de elecciones efectuadas entre distintas figuras terapéuticas, fármacos, doctrinas y representaciones del mal y de la terapia ${ }^{(5,14,32)}$. La lógica de estos procesos puede, sin embargo, ser reconstruida a posteriori a través de un estudio en el que se profundice caso a caso, y en el que cada acción o etapa del recorrido se coloque en relación con un contexto más amplio. Estas páginas propusieron y testearon la validez de un abordaje que permite desarrollar ese análisis. Examinamos aquí los elementos principales -acciones, elementos estructurales, factores situacionales- de la "representación" relativa a la acción de un fantasma que, en 2006, se manifestó en la cotidianidad de la familia garhwali.

Vimos cómo los actores involucrados, lejos de ser receptores pasivos de una forma impuesta, disponen de un poder de acción y concretan elecciones. Estas elecciones son dictadas por un saber práctico del que el sujeto no es siempre consciente. Esto es evidente, por ejemplo, en el modo en que Rajni es guiada por un conocimiento de las prácticas que le permiten aumentar y salvaguardar su propio honor en la casa del marido. Pero ese modo de funcionamiento se vuelve todavía más evidente en la observación del gesto de Anil que actúa sobre la base de un saber naturalizado e incorporado relativo, por un lado, a la posibilidad de que su madre sea víctima del ataque de un fantasma y, por el otro, a los comportamientos y los movimientos físicos que corresponden al médium de una divinidad.

Aun así, estas acciones, en tanto no están determinadas anticipadamente, no son puestas en acto en un campo neutro, sino en un contexto marcado por elementos estructurales -sistemas relacionales, roles prescriptos, representaciones, valores compartidos- que, al mismo tiempo, habilitan ciertas prácticas. Vimos cómo estos elementos determinan la 
probabilidad del éxito de una acción y de una interpretación. En el caso descripto, algunas estructuras que caracterizan la sociedad garhwali -por un lado, las representaciones compartidas sobre la naturaleza del sujeto femenino y de los fantasmas y, por otro, la condición al mismo tiempo sometida y ambigua de la mujer casada que alimenta un sentimiento colectivo permanente de ansia alrededor del comportamiento femeninofuncionan como potenciales puntos de soporte para que emerja la explicación causal que saca a relucir al fantasma para explicar el dolor de Rajni.

Finalmente, el análisis permitió preguntarse sobre la relación entre el primer conjunto de factores mencionados del orden de la acción y, el segundo, del orden de la estructura y de las representaciones compartidas en el proceso que "da vida" al fantasma. El caso analizado en este texto muestra cómo la relación entre estos elementos no puede ser comprendida sin tomar en consideración la importancia del contexto situacional y de la interacción intersubjetiva. A través de la interacción con los otros actores y en el contexto situacional (en correspondencia con cierta actividad agrícola y otros eventos) el individuo adapta su conducta y redefine sus propias prioridades, siempre en los límites impuestos por el orden estructural. La relación entre potencialidad de acción y orden estructural se configura entonces no solo como dialéctico, sino como dialógico. Esto es evidente en el caso de Rajni que, a medida que la posesión de Anil es aceptada como auténtica y que la hipótesis del fantasma se impone como verdadera, decide someterse a esa interpretación con obediencia.

El análisis de este caso de enfermedad permitió sacar a la luz que, el hecho de que el fantasma se haya impuesto como causa de un síntoma no es, en el contexto local, totalmente previsible ni está completamente determinado, ni tampoco es del todo causal. El éxito de esta explicación no depende de la aplicación mecánica de ciertas causas a determinados efectos. Aun así, no es independiente de factores estructurales. Existen altas probabilidades de que la acción de un fantasma prevalezca sobre otras causas posibles del problema, en ciertos casos específicos: aquellos en los cuales, como en el episodio analizado, el control de la mujer y de sus desplazamientos están en juego.

Las historias de fantasmas en Uttarkhand, que invocan su accionar para explicar problemas de salud u otros eventos no deseados que afectan la vida de los hombres y, sobre todo, de las mujeres, no son anécdotas graciosas, sino más bien fenómenos ejemplares que permiten comprender los modos en que las interacciones intersubjetivas, en relación con un determinado contexto de relaciones y de representaciones compartidas, dan vida a una categoría interpretativa específica. 


\section{REFERENCIAS BIBLIOGRÁFICAS}

1. Naraindas H, Quack J, Sax WS, editors. Asymmetrical conversations: contestations, circumventions, and the blurring of therapeutic boundaries. Oxford: Berghahn; 2014.

2. Grmek M, editor. Histoire de la pensée médicale en Occident: Tome 1 Antiquité et Moyen Âge. Paris: Seuil; 1995.

3. Good B. Medicine, rationality, and experience: An anthropological perspective. Cambridge: Cambridge University Press; 1994.

4. Forster GM, Anderson BG. Medical Anthropology. New York: John Wiley \& Sons; 1978.

5. Benoist J, editor. Soigner au pluriel: Essais sur le pluralisme médical. Paris: Karthala; 1996.

6. Johanessen H, Lázár I. Multiple medical realities: Patients and healers in biomedical, alternative and traditional medicine. New York: Berghahn; 2006.

7. Orr D, Bindi S. Medical pluralism and global mental health. In: White RG, Jain S, Orr DMR, Read $U$, editors. The Palgrave handbook of global mental health: Socio-cultural perspectives. London: Palgrave-Macmillan; 2007.

8. Bindi S. La fabrique de l'événement: Paysage de possession, de soin et de production de sens dans la vallée du Baghirati (Garhwal, Inde du Nord). [Thèse Ethnologie]. Paris: EHESS, Università di Siena; 2009.

9. Kleinman A. Patients and healers in the context of culture: An exploration of the borderland between anthropology, medicine, and psychiatry. Berkeley: University of California Press; 1980.

10. Weiss M, Doongaji D, Siddhartha S, Wypij D, Pathare S, Bhatawdekar M, Fernandes R. The explanatory model interview catalogue (emic): Contribution to cross-cultural research methods. The British Journal of Psychiatry. 1992;160(1):819-830.

11. Dein S. Explanatory models and oversystematisation in medical anthropology. In: Littlewood $\mathrm{R}$, editor. The importance of knowing about not knowing. Walnut Creek, CA: Left Coast Press; 2007. p 39-53.

12. Young A. When rational men fall sick: An inquiry into some assumptions made by medical anthropologists. Culture Medicine and Psychiatry. 1981;5(4):317-335.

13. Halliburton M. Mudpacks and Prozac: Experiencing ayurvedic, biomedical and religious healing. Walnut Creek, CA: Left Coast Press; 2009.
14. Bibeau G, Corin E, Collignon R. Préface. In: Janzen JM. La quête de la thérapie au Bas-Zaïre. Paris: Karthala; 1995.

15. Fainzang S. Les stratégies paradoxales: Réflexions sur la question de l'incohérence des conduites des malades. Sciences Sociales et Santé. 1997;15(3):5-23.

16. Bourdieu P. Esquisse d'une théorie de la pratique: Précédé de trois études d'ethnologie kabyle. Genève: Droz; 1972.

17. Holland D, Lachichotte W, Skinner D, Cain C. Identity and agency in cultural worlds. Cambridge Mass: Harvard University Press; 1998.

18. Bindi S. Grandir aujourd'hui en Himalaya Indien: Des rituels au service d'une nouvelle adolescence. Ethnologie Française. 2015(154):715-724.

19. Polit K. Women of honour: Gender and agency among Dalit women in the Central Himalayas. New Delhi: Orient Blackswan; 2012.

20. Fainzang S. L'intérieur des choses: Maladie, divination et reproduction sociale chez les Bisa du Burkina. Paris: L'Harmattan; 1986.

21. Turner V. The anthropology of performance. New York: Paj Publication; 1986.

22. Nabokov I. Religion against the self: An ethnography of Tamil rituals. Oxford: Oxford University Press; 2000

23. Obeyesekere G. Psycho-cultural exegesis of a case of spirit possession from Sri Lanka. Contributions to Asian Studies. 1975;(8):44-89.

24. Ram K. Fertile disorder: Spirit possession and its provocation of the modern. Honolulu: University of Hawaii Press; 2013.

25. Lewis IM. Ecstatic religion: An anthropological study of spirit possession and shamanism. Harmondsworth: Penguin Books; 1971.

26. Leslie J. The perfect wife: The orthodox Hindu woman according to the Stridharmapaddhati of Tryambakayajvan. Delhi: Oxford University Press; 1989

27. Sax WS. Mountain goddess: Gender and politics in a Himalayan pilgrimage. New York: Oxford University Press; 1991.

28. Krengel M. Communication and gift exchange between wife-givers and wife-takers in Kumaon Himalaya. In: Joshi MP, Fanger AC, Brown C, 
editors. Himalaya: past and present. Almora: Shree Almora Book Depot; 1991. p. 267-286.

29. Freed S, Freed R. Spirit possession as illness in a North Indian village. Ethnology. 1964(3):152-171.

30. Harper EB. Spirit possession and social structure. In: Ratnam B, editor. Anthropology on the March. Madras: The Book Centre; 1963.
31. Stirrat R. Power and religiosity in a post-colonial setting: Sinhala Catholics in contemporary Sri Lanka. Cambridge: Cambridge University Press; 1992.

32. Fassin D. Pouvoir et maladie en Afrique. Paris: PUF; 1992.

\section{FORMA DE CITAR}

Bindi S. Fantasmas e inflamaciones: reflexiones sobre las interpelaciones terapéuticas a la religión en India. Salud Colectiva. 2018;14(2):179-192. doi: 10.18294/sc.2018.1570.

Recibido: 21 de agosto de 2017 | Versión final: 3 de abril de 2018 | Aprobado: 29 de mayo de 2018

Este obra está bajo una licencia de Creative Commons Reconocimiento-NoComercial 4.0 Internacional. Reconocimiento - Permite copiar, distribuir y comunicar públicamente la obra. A cambio, se debe reconocer y citar al autor original. No Comercial - Esta obra no puede ser utilizada con finalidades comerciales, a menos que se obtenga el permiso.

http://dx.doi.org/10.18294/sc.2018.1570

Este texto fue traducido del italiano por Verónica Giménez Béliveau. 